\title{
Continuous Identification of a Four-Stroke SI Engine
}

\author{
Melgaard, Henrik; Hendricks, Elbert; Madsen, Henrik
}

Published in:

American Control Conference

Publication date:

1990

Document Version

Publisher's PDF, also known as Version of record

Link back to DTU Orbit

Citation (APA):

Melgaard, H., Hendricks, E., \& Madsen, H. (1990). Continuous Identification of a Four-Stroke SI Engine. In American Control Conference (pp. 1876-1881). IEEE.

\section{General rights}

Copyright and moral rights for the publications made accessible in the public portal are retained by the authors and/or other copyright owners and it is a condition of accessing publications that users recognise and abide by the legal requirements associated with these rights.

- Users may download and print one copy of any publication from the public portal for the purpose of private study or research.

- You may not further distribute the material or use it for any profit-making activity or commercial gain

- You may freely distribute the URL identifying the publication in the public portal

If you believe that this document breaches copyright please contact us providing details, and we will remove access to the work immediately and investigate your claim. 


\title{
CONTINUOUS IDENTIFICATION OF A FOUR-STROKE SI ENGINE
}

\author{
H. Melgaardt, E. Hendricks* and H. Madsen $\dagger$ \\ tInstitute of Mathematical Statistics and Operations Research \\ *Institute of Automatic Control Systems \\ The Technical University of Denmark \\ DK-2800 Lyngby, Denmark
}

\begin{abstract}
Abtract
Compact engine models often consiat of a set of nonlinear differential equations which predict the time development of the mean value of the engine state variables (and perhapa some internal variables): such models are sometimes called mean value engine models. Currently a great deal of attention in focused on constructing such continuous time modeb and on finding their parameters. This papez ahows, that it is poesible to identify an engine model from a linearized version of a mean value model for a CFI four-cycle spart ignition (SI) engine. Such an approsech is useful because it preserves a physical nnderstanding of the engine throughout the identification stage. Afterwards the identification results are available for general dynamic engine studies.
\end{abstract}

The identification techniques discused in this paper include classical methods (step responec) as well as modern statistical methods (Kalman filtering and Maximum Likelihood estimation). These techniques have been applied to a four cylinder SI engine. The results include an identification of the most important parameters and time constants of the engine. These are of interest for the construction of engine simulation models, for control studies and condition monitoring applications.

\section{Intratection}

In spite of the great interest which exists in identifying the parameters of engines (and in particular epark ignition engines), there is very little work of this nature reported in the literature. This is mainly because

1. an engine is a nonlinear aystem which is diffieult to describe phyically and

2. an engine is very noiny control object which requires the use of advanced dynamic tatiatical identification techniques.

These difficulties are reflected in the rather spare collection of literature references in this ares and in the large variety of engine and engine model types treated in that which is available. The modeb identified range from very simple continuous or discrete transfer function modets to linearized continuous mean value engine models. Mean value engine models are continuous dynamic models which predict the mean value of important engine variables several engine cycles.

Among the simplest types of model identified one can mention thoee which have appeared in connection with adaptive control studies. Examples of ach models are the work of Olsoon, et. al., (1981) and Welletead and Zanker, (1981). Both the models and the identification techniques in wech models are very simple and unsophisticated as an adaptive algorithm is meant to run on-line, in parallel with an operating engine. The physical content of the models and their accuracy in correspondingly limited.

Wellstead, et. a., (1978) have used a simple continuous transfer function model in their digital frequency response identification of a turbocharged diesel engine. Frequency response methods were also used by Chin and Costs, (1986) to identify the dynamics of an SI engine transformed to the crank shaft domain. Such investigations are very useful at isolated operating points and reasonable engine transfer functions can be obtained. The procedure is however very time consuming both as regards experimental time as well as computer analysis.

Time domain identifications have been undertaken by Hopkins and Borcherts, (1980), Morris, et. al., (1981) and Coo, et. al., (1986). The approach of Hopkins and Borcherts (1980) is to use simplified discrete difference equations and Landau's model reference adaptive algorithm. This yields reasonable results for a single engine at different operating points, but yields very little physical understanding of the model obtained or of its parameters. Morris, et. al., (1981) use the same approach but start with a more physical model. While this does yield results which can be interpreted physically, the discretization of the engine model involved collects the desired engine parameters into discrete transfer function coefficients which are difficult to unravel. Cas, et. al., (1986) use an RLS algorithm to estimate engine parameters directly in a discrete model. While this algorithm is useful on line, the modets identified are simple difference equation approximations to the physical engine.

This paper describes an identification of a continuous time linearized engine model ving Maximum Likelibood (ML) methods. The ML algorithm is used in conjunction with a Kalman filter to cotimate the states and noise covariances iteratively for the ML algorithm. The identified parameters are thoee of a continuons rather than a discrete time model. While this a large algorithm which is used off-line here, it can be converted into a recursive form. In any case it does yield phyrical engine parameters with good aceuracy at widely spread operating points.

\section{Model Pouglation}

In order to succesafully extimate parameters in a model of a dynamic system, it is very important at the experimental deaign tage to define the frequency ranges of the important dynamic engine subeystems. This bes to be done, since for preckieal estimation it is not possible to extimate simultaneously time constants which differ too widely at the same time. In the table below, the characteristic frequency ranges of the moet important SI engine raboyatems are tabulated.

\begin{tabular}{|c|c|c|}
\hline engine abojitem & aboyiden bandwidth & \\
\hline $\begin{array}{l}\text { temperature changea } \\
\text { rotational dynamics } \\
\text { fuelfow dynamics } \\
\text { manifold filling } \\
\text { noise from crankshaft rotations } \\
\text { noise pulses from piston } \\
\text { noise from bearings, gear etc. }\end{array}$ & $\begin{array}{ll}\sim & 0.01 \\
\approx & 0.2 \\
\sim & 2 . \\
\sim & 20-200 \\
\approx & 20-80 \\
\sim & 30-170 \\
\sim & 400-600\end{array}$ & $\begin{array}{l}\mathrm{Hz} \\
\mathrm{Hz} \\
\mathrm{Hz} \\
\mathrm{Hz} \\
\mathrm{Hz} \\
\mathrm{Hz} \\
\mathrm{Hz}\end{array}$ \\
\hline
\end{tabular}

Table 1: The characteristic frequency ranges of the most important subsystems of a SI engine (Collacott, 1977 pp 170-178; Hendricks and Sorensen, 1990). 
For control and condition monitoring applications the fuel flow and rotational dynamic subeystems are the most important identification objects. This is because the fuel flow dynamics are of great significance for air/fuel ratio $(\lambda)$ control, while the crank shaft dynamics determine an engine's drivability characteristics. The crank shaft dynamies also reflect the condition of the engine. Temperature effects will be ignored here.

The model for the crank shaft speed is based on a linearisation proposed by Cook and Porrell (1987). In this continuous mean value model, it is possible to neglect the injection to power delay. For a four cylinder, four $\rightarrow$ troke engine this delay is $T_{i p}=$ $30 / \mathrm{n}[\mathrm{rpm}]$. At $3000 \mathrm{cpm}$ this delay is $\sim 0.01 \mathrm{sec}$ which, when compared to the time constant for the rotational dynamics $\tau_{r} \sim 4$ sec, is negligible.

The fuel flow dynamic submodel for a CFI engine has been identified in the literature using classical identification techniques (Aquino, 1981). It has not yet been the subject of a study using modern techniques. For this study Aquino's model (with modifications) has been used as the basic identification object. The model is a semi empirical representation of the behavior of the fuel film in the intake manifold. It is asumed that the intake manifold is heated by the engine coolant. A block diagram of the fuel flow subsystem is shown at the top of figure 1.

As indicated on the figure, the injected fuel mass flow, $\dot{\mathrm{m}}_{\mathrm{f} i}$, divides into two contributions: a vapor phase mass flow, $\dot{\mathrm{m}}_{\mathrm{fv}}$, and a liquid phase mass flow, $\dot{m}_{\mathrm{ff}}$ (which is the fuel film). The proportion of the fuel which goes into the fluid phase is $X(0 \leq X$ $\leq 1)$ while the remaining proportion $(1-X)$ is entrapped in the air stream as vapor. The time constant, $\tau_{f} y$, which describes the dynamics of the entrapment process is expected to be of the same order as the manifold filling dynamics. The time constant, $\tau_{\mathrm{ff}}$, describes the mean evaporation time for the fuel film flow from the intake manifold.

In order to complete the fueling dynamics submodel, a model for the dynamies of the lambda sensor (and its aseociated electronics) must be given. Lambda is the air/fuel mass ratio normalized with the ratio at stoichiometric conditions: $\lambda=\dot{\mathbf{m}}_{\mathrm{a}} /\left(\dot{\mathrm{m}}_{\mathrm{f}} \mathrm{L}_{\mathrm{th}}\right)$, where $\mathrm{L}_{\mathrm{th}}=14.67$ is the mass ratio for a stoichiometric mixture, $\dot{\mathrm{m}}_{\mathrm{a}}$ is the air mass flow and $\dot{m}_{f}$ is the fuel mase flow at the cylinder intake valve. The dynamics of the lambda sensor will be approximated by a pure time delay, $\Delta t$, in this paper for simplicity. Thus $\lambda_{\Delta_{t}}$ is lambda measured by a linear lambda sensor, delayed the time $\Delta t$, which is the delay time for exhaust gases to pass through the exhaust valves and down to the lambda sensor.

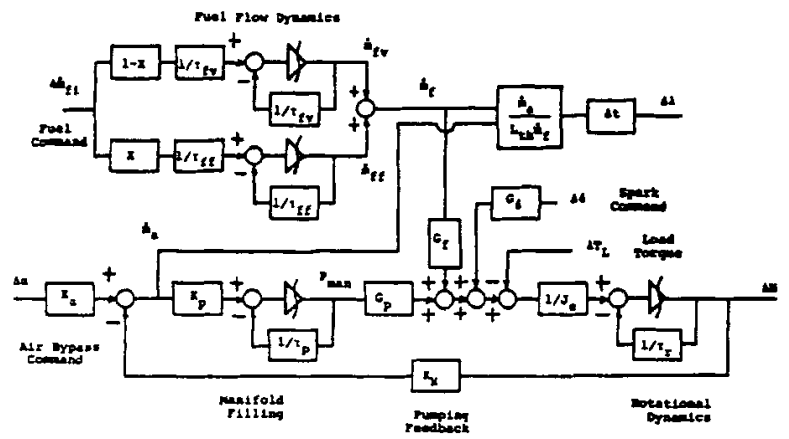

Fig. 1: Block diagram of the overall engine model. All input and state variables are linearized around their mean values, i.e., $\Delta \mathbf{z}=$

$z-\bar{z}$ ( $\bar{z}$ is the mean value of $z$ ). In this block diagram the process and measurement noises are omitted for clarity. Noise is of course included in the state space formulation and considered in the model estimation.

\section{Meacurement Setep}

The experiments were conducted on a four cylinder, four-stroke , 1.1L Ford CFI engine mounted on an eddy current dynamometer. The engine was fully equipped with sensors for all the relevant engine input and output variables. The air/fuel ratio was measured with a NTK Micro Oxivision MO-1000 Air/Fuel Ratio Meter with its own linear $\lambda$ sensor. All engine inputs and outputs were connected to a PC-AT based data acquisition system. All experiments were conducted under open loop conditions.

To keep the engine at the desired identification (operating) point, the engine was given constant input biases (fuel flow, spark angle BTDC and throttle angle). For the step response experiments a deterministic square wave perturbation was superimposed on the desired input, with a maximum amplitude of $\pm 10 \%$ of the relevant bias level. In the statistical identification experiments a corresponding PRBS (Pseudo Random Binary Sequence) perturbation was superimpoeed. The PRBS signal may switch between two constant levels only at certain equally spaced time intervals, $t=0, T_{\text {prbs }}, 2 T_{\text {prbs }} \ldots$. Its frequency characteristics are determined by selecting the time period $T_{p r b s}$ and the order of the signal, $n$. These parameters determine the frequency limits for the signal. A useful rule of thumb is, that it is possible to estimate time constants in the interval $T_{\text {prb6 }} / 10<t<2 n T_{\text {prbs }}$ (Madsen, 1988) given a reasonable sampling period, $T_{5}$. For the experiment to be reviewed, $T_{\mathrm{prbs}}=0.5 \mathrm{sec}$ and $\mathrm{n}=6$ have been selected, thus it should be possible to estimate time constants in the approximate interval 0.05 sec to 6 sec. In order to avoid aliasing effects, all the data logging channels are prefiltered with identical fourth order analogue filters, with a bandwidth of $20 \mathrm{~Hz}$. The sampling frequency was selected as four times this bandwidth, i.e., $T_{s}=0.0125$ sec.

\subsection{Clasical Identifieation Experiments}

Before initiating a series of experiments aimed at using complicated identification algorithms, it is always advisable to attempt to use simpler classieal methods. This is desirable in order to check the feasibility of the basic model and to what problems might arise in the use of a more sophisticated method.

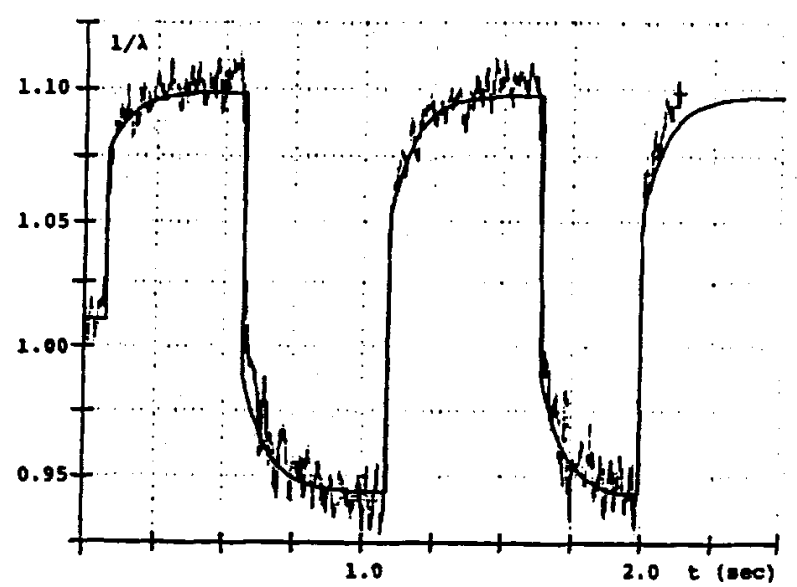

Fig. 2: The result of atep response test. For comparison the simulation result from an equivalent deterministic square wave input is plotted together with the experimental time response.

The results of a typical classical step response test are displayed on figure 2. The fuel injector is being driven here by a rather large manually generated square wave perturbation with an amplitude which is $\pm 10 \%$ of the fuel bias amplitude. $1 / \lambda$ is plotted proportional to the intake valve fuel mass flow. Thus the 
dynamic port fuel flow is being observed directly in this experiment. For comparison the response of the model of figure 1 (with $\tau_{\mathrm{fv}}=0$ ) to an equivalent equare wave input is plotted together with the experimental results. The time delay $\Delta t$ has been suppresed for clarity. Here the throttle angle is $43.5^{\circ}$ and the crank shaft speed is $3380 \mathrm{rpm}$. The time constant, $T_{\mathrm{ff}}$, for the simulation is $0.25 \mathrm{sec}$ and the proportion of fuel which goes into the fluid phase, $X$ is 0.22 . It may be seen that the agreement is excellent during the entire experiment except for a small deviation at the beginning of the lean excursions of the square wave. This is due to the slight physical differences between rich and lean evaporation conditions. Figure 2 and a large number of similar results suggest that the simple model gives a sufficient description of the physics of the intake manifold. The results of the step response tests abo show that due to noise and the response time of the $\lambda$ sensor, it is very difficult to obtain sufficiently accurate parameter estimates in this way. In order to obtain greater accuracy it is neceseary to resort to more advanced methods.

\section{Maximum Litelibood Method for Parameter Primation}

The maximum likelihood method is used to solve the parameter estimation problem. This section describes how the parameters of the continuous engine model are found by using diacrete measurements and the marimum likelibood method. As a starting point the model is reformulated as a linear stochastic state space nodel, where the stochastic portion accounts for discrepancies of the model compared to the true aystem. Secondly, the discrete version of the continuous stochastic model is obtained in order to evaluate the likelihood function. The likelihood function is then expressed as a product of conditional densities, which are evaluated by using a Kalman filter. Numerical methods have been used for the optimination of the likelihood function. The asymptotic properties of the maximum likelibood estimator make possible a parallel evaluation of the uncertainty of the catimated parameters.

\subsection{Linear Stoch tic Models in State Space}

The dynamica of the engine can be parameterived vis the linearized state space model in continuous time

$$
\frac{d X}{d t}=A X+B v
$$

where $\mathrm{X}$ is the state-vector and $\mathrm{U}$ is the input vector.

Some description of the discrepancies between the model (1), and the true variation of the sates is introduced by adding a noise term. Then the model of the engine dynamies is deacribed by the sochetic differential equation

$$
d X=A X d t+B U d t+d w(t)
$$

where the m'th dimensional stochatic proces $w(t)$ is asoumed to be a process with independent increments. With the purpose of calculating the likelihood function, $w(t)$ will be further reatricted to be a Wiener-process with the incremental covariance $R_{1}{ }^{\prime}(t) d t$.

In general, the measured or recorded variables are a subset of the state variables, and the measurements are encumbered with some measurement erross. Thus it is ascumed that only a linear combination of the states are measured. Let $Y$ denote the measured or recorded variables, then the measured variables are written

$$
Y(t)=C X(t)+e(t)
$$

where $\mathbf{C}$ is a matrix, which specifies which linear combination of the states that are actually measured. The term $e(t)$ is the measurement error. It is assumed that $e(t)$ is normal distributed white noise with zero mean and variance $R_{2}$. Furthermore it is assumed that $w(t)$ and $e(t)$ are mutually independent.

\subsection{From Continuous to Discrete Time}

The obeervations are discrete. Hence, the continuous model has to be evaluated at discrete time intervals in order to calculate the likelihood function. For the present method, where the system is assumed to be described by the stochastic differential equation (2) it is possible analytically to perform an integration, which under some asumptions exactly specifies the system equation in discrete time.

For the continuous model (2) the corresponding discrete model is obtained by integrating the differential equation through the sample interval $[t, t+\tau]$. If $U(t)$ is constant in the sample interval the sampled version of (2) can be written exactly as the following discrete model in state space form

$$
X(t+\tau)=\phi(\tau) X(t)+\Gamma(\tau) U(t)+v(t ; \tau)
$$

where

$$
\begin{aligned}
& \phi(\tau)=e^{A \tau}, \quad \Gamma(\tau)=\int_{0}^{T} e^{A s} B d s \\
& v(t ; \tau)=\int_{t}^{t+\tau} e^{A(t+\tau-s)} d \tau(s)
\end{aligned}
$$

On the asumption that $\sigma(t)$ is a Wiener process, $v(t ; \tau)$ becomes normally distributed white noise with zero mean and covariance

$$
R_{1}(\tau)=E\left[v(t ; \tau) v(t ; \tau)^{\prime}\right]=\int_{0}^{\tau} \phi(s) R_{1}^{\prime} \phi(s)^{\prime} d s
$$

If the sampling time in constant, the stochastic difference equation can be written

$$
x(t+1)=\phi x(t)+\Gamma v(t)+r(t)
$$

where the time scale now is transformed in such a way that the sampling time becomes equal to one time unit.

\subsection{Marim in Lifelibod Extimatea}

In the following it is asumed that the observations are obtained at regularly spaced time intervals, and hence that the time index $t$ belongs to the $\{0,1,2, \ldots, N\} . N$ is the number of observations. In order to obtain the likelikood function we introduce

$$
\mathbf{Y}(t)=[\mathbf{Y}(t), \mathbf{Y}(\mathbf{t}-1), \ldots, \mathbf{Y}(1), \mathbf{Y}(0)]^{\prime}
$$

i.e. $Y(t)$ is a matrix containing all the obeervations up to and including time $t$. Finally, let $\theta$ denote a vector of all the unknown parameters - including the unknown variance and covariance parameters in $\mathbf{R}_{1}$ and $\mathbf{R}_{2}$.

The likelibood function is the joint probability density of all the observations assuming that the parameters are known, i.e.

$$
\begin{aligned}
L^{\prime}(\theta, Y(N)) & =p(Y(N) \mid \theta) \\
& =p(Y(N) \mid Y(N-1), \theta) p(Y(N-1) \mid \theta) \\
& =\left[\prod_{t=1}^{N} p(Y(t) \mid Y(t-1), \theta)\right] p(Y(0) \mid \theta)
\end{aligned}
$$

where successive applieations of the rule $P(A \cap B)=$ $P(A \mid B) P(B)$ are used to express the likelihood function a product of conditional densities. 
Since both $v(t)$ and $e(t)$ are normally distributed, the conditional density is also normal. The normal distribution is completely characterized by the mean and the variance. Hence, in order to parameterize the conditional distribution, we introduce the conditional mean and the conditional variance as

$$
\begin{aligned}
& \hat{\mathrm{Y}}(\mathrm{t} \mid \mathrm{t}-1)=\mathrm{E}[\mathrm{Y}(\mathrm{t}) \mid \mathbf{Y}(\mathrm{t}-1), \boldsymbol{\theta}], \\
& \mathrm{R}(\mathrm{t} \mid \mathrm{t}-1)=\mathrm{V}[\mathrm{Y}(\mathrm{t}) \mid \mathrm{Y}(\mathrm{t}-1), \boldsymbol{\theta}
\end{aligned}
$$

respectively. Equation (7) is the one step prediction and (8) the associated variance. Furthermore, it is convenient to introduce the one step prediction error (or innovation)

$$
\epsilon(t)=Y(t)-\hat{Y}(t \mid t-1)
$$

Using (6) - (9) the logarithm of the conditional likelihood function (conditioned on $Y(0)$ ) becomes

$$
\begin{gathered}
\log L(\theta, Y(N))=-1 / 2 \sum_{t=1}^{N}[\log \operatorname{det} R(t \mid t-1)+ \\
\left.\epsilon(t)^{\prime} R(t \mid t-1)^{-1} \epsilon(t)\right]+ \text { const. }
\end{gathered}
$$

The conditional mean $Y(t \mid t-1)$ and the conditional variance $R(t \mid t-1)$ are calculated recursively by using a Kalman filter (e.g. Åstrōm, 1970). The Kalman filter requires initial values, which describe the prior knowledge about the states of the system in terms of the prior mean and variance

$$
\begin{aligned}
& \dot{\mathrm{Y}}(1 \mid 0)=\mathrm{E}[\mathrm{Y}(1)]=\mu_{0} \\
& \mathrm{P}(1 \mid 0)=\mathrm{V}[\mathrm{Y}(1)]=\mathrm{V}_{0}
\end{aligned}
$$

For a given set of parameters, $\theta$, the likelihood function is evaluated by using the Kalman filter for a calculation of the the conditional mean and variance. The maximum likelihood estimate

(ML estimate) is the set $\dot{\theta}$ which maximizes the likelihood function. For the optimization of the likelihood function the IMSL routine DB2ONF (1988) was used.

An estimate of the uncertainty of the parameters is obtained by the fact that the ML estimator is asymptotically normally distributed with mean $\theta$ and variance

$$
\mathbf{D}=\mathbf{H}^{-1}
$$

where the matrix $\mathrm{H}$ is given by

$$
\left\{h_{1 k}\right\}=-E\left[\frac{\partial^{2}}{\partial \theta_{1} \partial \theta_{k}} \log L(\theta, Y(N))\right]
$$

An estimate of $D$ is obtained by equating the observed value with its expectation and applying

$$
\left\{\mathrm{h}_{1 \mathrm{k}}\right\} \approx-\left[\frac{\partial^{2}}{\partial \theta_{1} \partial \theta_{\mathrm{k}}} \log \mathrm{L}(\theta ; Y(\mathrm{~N}))\right] \mid \theta=\hat{\theta}
$$

The above equation is thus used for estimating the variance of the estimates. If an estimated variance is large compared to the actua estimated value for a parameter, this indicates that probably this nararneter can be eliminated from the model (the parameter is equal to sero). An asymptotic test can be based on the t-diatribution.

The estimated models are evaluated both statiatically and physically. The latter is discuseed in the next rection. The statistical methods used for evaluation rely on the fact that if all the systematic variation is described by a specific model, then the residuals will be white noise sequences. Both tests in the autoand croses correlation functions, and teats in the frequency domain were carried out. A further description of test procedures is found in e.g. Box and Jenkins (1976).

\section{Reants}

Since the engine inputs were perturbed one at a time (while the others were kept constant), it was poesible to identify submodels of the total model one after the other. Most attention was concentrated on the fuel flow submodel, because of it's great importance and deficient coverage in the literature.

The parameters of the model were estimated for 6 points in the normal engine operating region, for varying values of the throttle angle. In the experiment with perturbations in the injected fuel, the air flow is assumed to be constant, thus a straight-forward way of measuring the fuel flow into the cylinder intake valves, was again just to invert lambda. This value is proportional to the fuel mass flow.

$1 / \lambda_{\Delta t}=\frac{L_{t h} \dot{m}_{f}}{\dot{m}_{\mathrm{g}}} e^{-\Delta \Delta t}=$ const $\cdot \dot{m}_{\mathrm{f}} \mathrm{e}^{-\mathrm{s} \Delta \mathrm{t}}$, where $\dot{\mathrm{m}}_{\mathrm{a}} \simeq$ const.

The state space formulation of the submodel is

$$
\begin{aligned}
{\left[\begin{array}{l}
d_{\dot{m}_{f v}} \\
d_{\dot{m}_{f f}}
\end{array}\right] } & =\left[\begin{array}{cc}
-1 / \tau_{f v} & 0 \\
0 & -1 / \tau_{f f}
\end{array}\right]\left[\begin{array}{l}
\dot{m}_{f v} \\
\dot{m}_{f f}
\end{array}\right] d t \\
+ & {\left[\begin{array}{l}
(1-X) / \tau_{f v} \\
X / \tau_{f f}
\end{array}\right] \dot{m}_{f i} d t+\left[\begin{array}{l}
d \nabla_{f v}(t) \\
d w_{f f}(t)
\end{array}\right] } \\
1 / \lambda_{\Delta t} & =\left[\begin{array}{ll}
K_{b} & K_{b}
\end{array}\right]\left[\begin{array}{l}
\dot{m}_{f v}(t-\Delta t) \\
\dot{m}_{f f}(t-\Delta t)
\end{array}\right]+e(t)
\end{aligned}
$$

\begin{tabular}{|c|c|c|c|c|c|c|}
\hline exp. & $\mathrm{n}$ & $a$ & $\Delta \dot{i}$ & $\dot{f}_{\text {TV }}$ & $\hat{t}_{f f}$ & $\dot{\mathbf{x}}$ \\
\hline f1 & 2931 & 29.5 & 0.0625 & $\begin{array}{c}0.0750 \\
\left(2,45 \cdot 10^{-6}\right)\end{array}$ & $\begin{array}{c}0.375 \\
\left(2.79 \cdot 10^{-6}\right)\end{array}$ & $\begin{array}{c}0.175 \\
\left(8.24 \cdot 10^{-3}\right)\end{array}$ \\
\hline f2 & 3562 & 32.8 & 0.0375 & $\begin{array}{c}0.0788 \\
\left(4.19 \cdot 10^{-3}\right)\end{array}$ & $\begin{array}{c}0.338 \\
\left(6.94 \cdot 10^{-3}\right)\end{array}$ & $\begin{array}{c}0.184 \\
\left(3.35 \cdot 10^{-2}\right)\end{array}$ \\
\hline B & 2655 & 24.8 & 0.0750 & $\begin{array}{c}0.0502 \\
\left(5.63 \cdot 10^{-2}\right)\end{array}$ & $\begin{array}{c}0.211 \\
\left(6.56 \cdot 10^{-2}\right)\end{array}$ & $\begin{array}{c}0.073 \\
\left(8.05 \cdot 10^{-2}\right)\end{array}$ \\
\hline 14 & 3275 & 29.2 & 0.0500 & $\begin{array}{c}0.0916 \\
\left(1.75 \cdot 10^{-2}\right)\end{array}$ & $\begin{array}{c}0.275 \\
\left(1.82 \cdot 10^{-3}\right)\end{array}$ & $\begin{array}{c}0.150 \\
\left(1.22 \cdot 10^{-1}\right)\end{array}$ \\
\hline 77 & 3201 & 36.5 & 0.0375 & $\left(5.37 \cdot 10^{-3}\right)$ & $\begin{array}{c}0.289 \\
\left(3.19 \cdot 10^{-3}\right)\end{array}$ & $\begin{array}{c}0.218 \\
\left(1.48 \cdot 10^{-2}\right)\end{array}$ \\
\hline 18 & 2676 & 24.7 & 0.0750 & $\begin{array}{c}0.0928 \\
\left(4.22 \cdot 10^{-8}\right)\end{array}$ & $\begin{array}{c}0.289 \\
\left(9.98 \cdot 10^{-5}\right)\end{array}$ & $\begin{array}{c}0.067 \\
\left(6.56 \cdot 10^{-1}\right)\end{array}$ \\
\hline
\end{tabular}

where $w_{f v}(t)$ and $w_{f f}(t)$ are Wiener-processes, with incremental variances $\sigma_{11}^{2}$ and $\sigma_{12}^{2}$, and $\mathrm{e}(\mathrm{t})$ is normal distributed white noise, with variance $\sigma_{2}^{2}$ (see figure 1 ).

Table 2: The estimation results are shown with the standard error of the estimates in brackets. $n$ is the engine speed in rpm, $\alpha$ is the throttle angle in degrees. The values of the delay, $\Delta t$, and the two time constants are in seconds. The constant $K_{b}$ is in $\mathrm{sec} / \mathrm{g}$ and the two process variances are in $(\mathrm{g} / \mathrm{sec})^{2}$. 


\begin{tabular}{|c|c|c|c|c|}
\hline $\exp$. & $\partial_{1}-10^{-2}$ & $\hat{A}_{2} \cdot 10^{-3}$ & $2 \cdot 10^{-4}$ & $\hat{\mathbf{K}}_{\mathbf{b}}$ \\
\hline n & $\begin{array}{c}0.1098 \\
\left(2.12 \cdot 10^{-7}\right)\end{array}$ & $\begin{array}{c}0.3910 \\
\left(1.04 \cdot 10^{-t}\right)\end{array}$ & $\begin{array}{c}1.2570 \\
(2.84 \cdot 10-9)\end{array}$ & $\left(\begin{array}{c}0.8421 \\
\left(1.05 \cdot 10^{-5}\right.\end{array}\right)$ \\
\hline$t$ & $\begin{array}{c}0.3591 \\
\left(1=6 \cdot 10^{-4}\right)\end{array}$ & $\begin{array}{c}0.1206 \\
\left(204 \cdot 10^{-3}\right)\end{array}$ & $(231 \cdot 10-9)$ & $\begin{array}{c}0.7211 \\
\left(7.80 \cdot 10^{-5}\right)\end{array}$ \\
\hline$B$ & $\stackrel{0.0751}{(1.4 \cdot 10-5)}$ & $\begin{array}{c}1.2010 \\
\left(4.20 \cdot 10^{-7}\right)\end{array}$ & $\begin{array}{c}0.8106 \\
(3.57 \cdot 10-6)\end{array}$ & $\frac{1.1937}{\left(3.71 \cdot 10^{-2}\right)}$ \\
\hline 4 & $\begin{array}{c}0.1978 \\
\left(2.85 \cdot 10^{-4}\right)\end{array}$ & $\begin{array}{c}24760 \\
\left(1.46 \cdot 10^{-3}\right)\end{array}$ & $\begin{array}{c}0.6732 \\
\left(1.44 \cdot 10^{-7}\right)\end{array}$ & $\begin{array}{c}0.8568 \\
\left(1.31 \cdot 10^{-1}\right)\end{array}$ \\
\hline 77 & $\begin{array}{c}1.6750 \\
\left(1.66 \cdot 10^{-1}\right)\end{array}$ & $\begin{array}{c}0.2281 \\
\left(2.04 \cdot 10^{-5}\right)\end{array}$ & $\frac{0.2001}{\left(2.31 \cdot 10^{-9}\right)}$ & $(7.64 \cdot 10-0)$ \\
\hline 18 & $\begin{array}{c}0.1333 \\
\left(1.52 \cdot 10^{-7}\right)\end{array}$ & $\begin{array}{c}0.6240 \\
\left(4.24 \cdot 10^{-8}\right)\end{array}$ & $\frac{0.7682}{\left(1.11 \cdot 10^{-1}\right)}$ & $\begin{array}{c}1.1609 \\
\left(1.36 \cdot 10^{-4}\right)\end{array}$ \\
\hline
\end{tabular}

It can be obeerved that for come of the parameters a cloce relation exists between the parameter values and the operating point. For example, the delay is lese for higher engine epeed: this is ahow on figure 3.

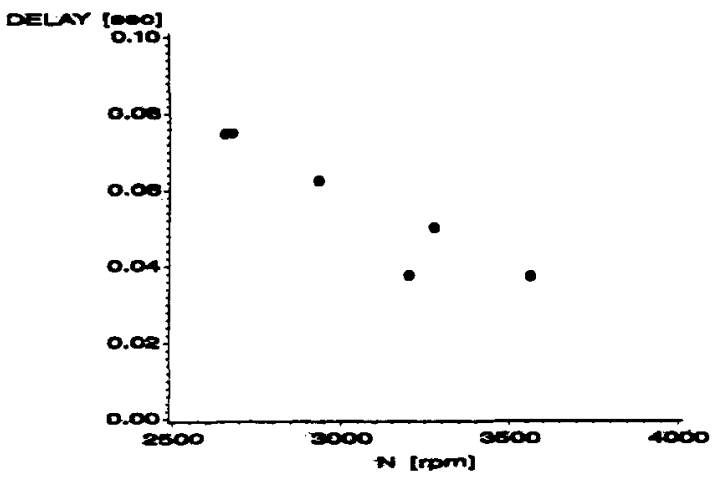

Fig. 3: A plot of the delay, $\Delta t$ versass the engine speed. There is some quantization nncertainty, aince the delay can only be estimated as whole number multipliers of the sampling time, i.e. $\Delta \mathbf{t}=\mathbf{n} \mathbf{T}_{\mathbf{s}}$

Similarly the $X$ parameter is abvioudy related to the throttle angle. A larger throttle angle implies a lurger fraction of liquid fuel in the manifold, shown by frare 4.

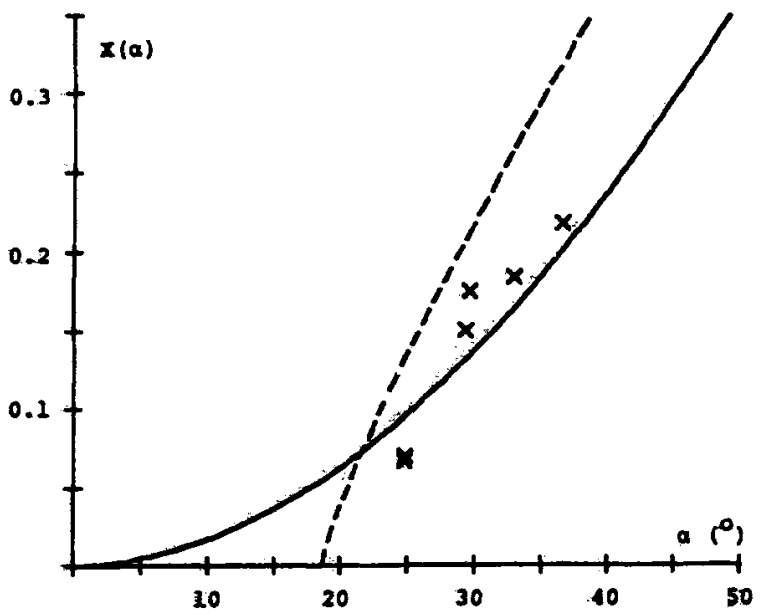

Fis 4: Identification of the funetion $X(\alpha)$ for the 1.1L Ford CFI engine. The expresions of Hendrieks and Soreneon $(\longrightarrow)(1990)$ and Wu, et. al.(___ $(1983)$ are plotted for comparion with the meacured points $\left(x^{\prime} \mathrm{s}\right)$.

No obvious functional relationehips are seen between the two time constants in the submodel and the operating point. The mean values for the two time contants in the operating region are $\tau_{\mathrm{fv}}$ $=0.085 \mathrm{ecc}$ and $T \mathrm{ff}=0.296 \mathrm{sec}$. Both time constants are oensibly constant from one identification run to another Obviously the variance eatimates of the process and measurement noise are varying. This is probably due to the different realizations of the noise processes from one experiment to another. In order to illustrate the performance of the model, figure 5 shows the one step predictions (performed by the Kalman filter) together with the oboerved output.

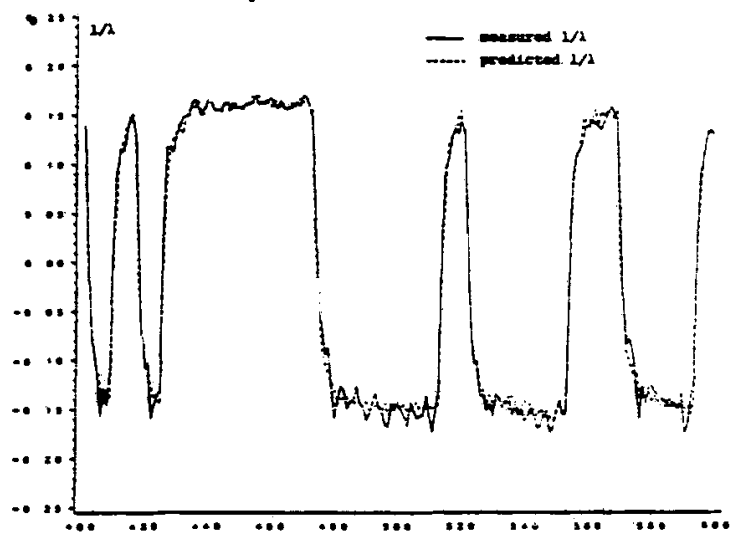

Fic. 5: A plot of the one atep predictions and the measured values of $1 / \lambda$ versos obeervation number. Notice that only a amal part of the time series of obeervations is shom, otherwise it would be difficult to distinguish the carves. Sumple time is $\mathbf{6 2 . 5}$ meec.

An extimation of the ocher sabmoael, descnbang vanatuons in crank shait apeed when the throttle angle is perturbed has been performed to show the posibility of estimating other model parameters. The manifold presure is joined as an output, since this value was actually measured. The manifold filling dynamics are very fast and can be neglected (the time constant for the rotational dynamics is around 4 sec while the time constant for the manifold filling is leas than $0.02 \mathrm{ecc}$ ). Hence it is leas significant than both of the time constants in the fuel How abmodel. The resulting model in state space form is then

$$
\begin{aligned}
& \mathrm{dN}=\left[-1 / T_{\mathrm{r}}-\mathrm{G}_{\mathrm{p}} \mathrm{K}_{\mathrm{n}} / \mathrm{J}_{\mathrm{e}} \mathrm{Ndt}+\left[\mathrm{G}_{\mathrm{p}} \mathrm{K}_{\theta}-1 / \mathrm{J}_{\mathrm{e}}\right]\left[\begin{array}{l}
0 \\
\mathrm{~T}_{1}
\end{array}\right] \mathrm{dt}+\mathrm{dw}(\mathrm{t})\right. \\
& {\left[\begin{array}{l}
\mathrm{N} \\
\mathrm{P}_{\text {man }}
\end{array}\right]=\left[\begin{array}{c}
1 \\
-\mathrm{K}_{\mathrm{n}}
\end{array}\right] \mathrm{N}+\left[\begin{array}{cc}
0 & 0 \\
\mathrm{~K}_{0} & 0
\end{array}\right]\left[\begin{array}{l}
0 \\
\mathrm{~T}_{1}
\end{array}\right]+\left[\begin{array}{l}
e_{1}(t) \\
e_{2}(t)
\end{array}\right]}
\end{aligned}
$$

where $w(t)$ is a Wiener proces with ineremental variance $\sigma^{2}$, and $e_{1}(t)$ and $e_{2}(t)$ are nownal ditributed white noine, with the covariance

$$
R_{2}=\left[\begin{array}{cc}
\alpha_{11}^{2} & 0 \\
0 & \sigma_{22}^{2}
\end{array}\right]
$$

The etimated parameter are shown below, with the soceiated andard erros in brackets.

$$
\begin{aligned}
& \hat{T}_{\mathrm{r}}=4.1358 \mathrm{sec} \\
& \hat{j}_{e}=0.6028(\mathrm{Nm} \mathrm{s} / \mathrm{rpm}) \\
& \hat{G}_{\mathrm{p}}=6.3570(\mathrm{Nm} / \mathrm{kPa}) \\
& \hat{K}_{\mathrm{p}}=0.008746(\mathrm{kPa} / \mathrm{rpm}) \\
& \hat{\mathrm{K}}_{\theta}=3.6403(\mathrm{kPa} / 0) \\
& \hat{\sigma}_{1}=74.70(\mathrm{rpm})^{2} \\
& \hat{\sigma}_{\mathrm{Z}}=14.43(\mathrm{pm})^{2} \\
& \hat{\sigma}_{22}=0.6988(\mathrm{Pas})^{2}
\end{aligned}
$$


It is seen, that the time constant for the rotating dynamics has been estimated to be $\tau_{\mathrm{r}}=4.1358 \mathrm{sec}$. It is thus clear that with the method described here it is poesible to estimate some parameters, that otherwise would be quite difficnlt to measure.

To demonstrate the overall performance of the model, a plot of the one step predictions performed by the Kalman filter is shown on figure 6 together with the observed values. The curves show very good agreement.

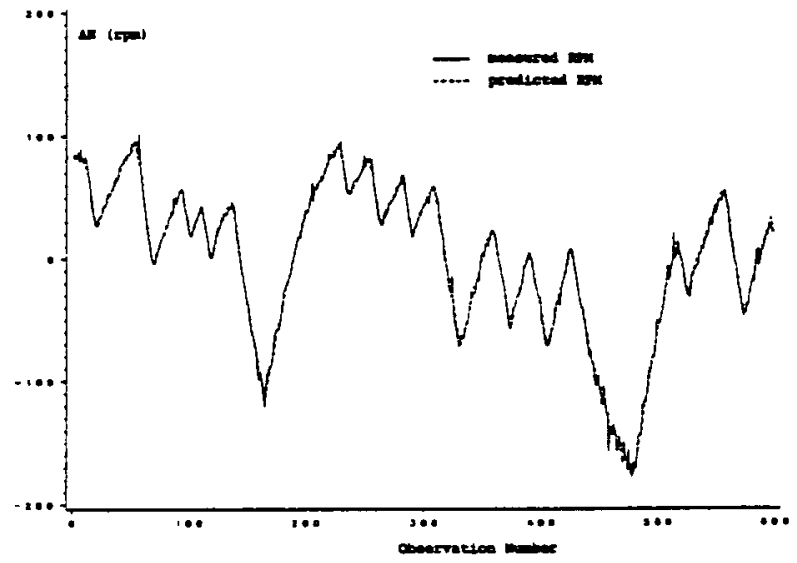

Fig. 6: One step predictions of the engine speed, $N$ and the measured values of $\mathrm{N}$ versus observation number. The sample time is 62.5 msec.

\section{Conclusions}

In this paper a procedure has been proposed for the identification of continuous model for engine dynamics based on discrete time data. The fact that the model formulation and estimation take place in continuous time makes it easy to use physical intuition during the identification process. Thus the model can be iteratively improved by combining physical knowledge and statistical data analysis. In addition the accuracy of the parameters is estimated at the same time as the parameters themselves. The problem of sufficiency and over parameterization is readily answered by analyzing the residuals and by considering the variances of the estimates. The estimates of the noise variances are useful in constructing Kalman filters for condition monitoring and control applications.

There are a number of applications for the identification results themselves. It is clear that in finding the internal variables of an engine (such as the thermal and volumetric efficiencies), the algorithm above can be useful for condition monitoring applications. If the algorithm is written in a recursive form, it is possible to use it on-line in a microprocessor either at a service facility or (in a reduced form) in an on-board engine control microprocessor.

Currently the algorithm is in use to identify and refine a mean value engine model developed in part by one of the authors (IIendricks and Sorenson, (1990)). Here the method has made accessible some details of engine operation characteristics, which were only inaccurately known earlier. This has improved the quality of the nonlinear model for control studies.

\section{References}

Aquino, C.F. (1981), "Transient A/F Control Characteristies of the 5 Liter Central Fuel Injection Enginen. SAE Technical Paper No olvay4, ibol

Aström, K.J. (1970), "Introduction to Stochastic Control Theory", Academic Press, 1970.
Box, G.E.P., and G.M. Jenkins (1976), "Time Series Analysis, Forecating and Control", Holden-Day, 1976.

Cao, C.T., Janetzke,H. and Schulz,A. (1986), "Einsats von Identifikationsverfahren im Kraftfahrzeugbereich", Automatisierungstechnik at, Vol. 34, No. 9, 1986.

Collacott, R.A. (1977), "Mechanical Fault Diagnosis and Condition Monitoring". Chapman and Hall, pp 170-178, 1977.

Cook, J.C. and Powell, B.K. (1983), "Nonlinear Low Frequency Phenomenological Engine Modeling and Analysis". American Control Conference, WA10, 1983.

Cook, J.C. and Powell, B.K. (1988), "Modelling af an Internal Combustion Engine for Control Analysis". IEEE Control Systems Magasine, aug. 1988.

Hendricks, E. and Sorenson, S.C. (1990), "Mean Value Modelling of Spark Ignition Engines", to be published, 1990.

Hopkins, H.G. and Borcherts, R.H. (1980), "Discrete Time Modelling of the Torque Response of a Spark-Ignited Fuel-Injected Engine", Applications of Adaptive Control, Narendra and Monopoli (eds), Academic Press, 1980.

Kiencke, U. (1987), "The Role of Automatic Control in Automotive Systems". IFAC 10th Triennial World Congress, Munich, FRG, 1987.

Madsen, H. and Schultz, J.M. (1988), "A Method for Identification of Continuous Time Models for Heat Dynamics of Buildings. Experimental Design and Test Results". Preliminary version for presentation at the CEC PASSYS subgroup testmethodologies meeting in Stuttgart, sept. 1988.

Moler, C. and Van Loan, C. (1978), "Nineteen Dubious Ways to Compute the Exponential of a Matrix". SIAM Review, Vol. 20, No 4, pp 801-837, oct. 1978.

Morris, R.L., Hopkins, H.G. and Borcherts, R.H. (1981), "An Identification Approach to Throttle-Torque Modelling", SAE Technical Paper 810448, 1981.

Olsson, G., Cohen, A.I. and Rao, H.S. (1981), "An Approach to Air-Fuel Ratio Control for Automotive Engines using Self-Tuning Regulators", IEEE Conference on Decision and Control, FP7-2:30, 1981.

Powell, J.D. (1987), "A Review of IC Engine Models for Control System Design", IFAC 10th Triennial World Congress, Munich, FRG, 1987.

Servati, H.B. and Yuen, W.W. (1984), "Deposition of Fuel Droplets in Horizontal Intake Manifolds and the Behavior of Fuel Film on Its Walls". SAE Technical Paper 840239, 1984.

Wellstead, P.E., Thiruarooran, C. and Winterbone, D.E. (1978), "Identification of a Turbocharged Diesel Engine", Proc. 7th IFAC World Congress, Helsinki, Finland, 1978.

Wellstead, P.E. and Zanker, P.M. (1981), "Application of Self-Tuning to Engine Control", from Self-Tuning and Adaptive Control, Harris, C.J. and Billings (eds), Peter Peregrinus, Ltd, London, 1981.

Wu, H., Aquino, C.F. and Chou, G.L. (1983), "A 1.6 Liter engine and intake manifold dynamic model". ASME conference paper 83-WA/DSC-39, 1983.

Yuen-Kwok, C. and Coats, F.E. (1986), "Engine Dynamics: Time Based Versus Crank-Angle Based", SAE Technical Paper, $860412,1986$. 